\title{
Embryo Survival from Gossypol-Fed Heifers after Transfer to Lactating Cows Treated with Human Chorionic Gonadotropin
}

\author{
K. N. Galvão, J. E. P. Santos, ${ }^{1}$ A. C. Coscioni, S. O. Juchem, R. C. Chebel, W. M. Sischo, and M. Villaseñor \\ Veterinary Medicine Teaching and Research Center, University of California-Davis, Tulare 93274
}

\begin{abstract}
Objectives were to determine the effects of gossypol exposure during early embryo development on embryonic survival after transfer of frozen and thawed embryos to lactating dairy cows treated with human chorionic gonadotropin $(\mathrm{hCG})$. Holstein cows $(\mathrm{n}=269)$ were either treated or not treated with 3,300 IU of hCG on $\mathrm{d} 5$ of the estrous cycle and received an embryo collected from heifers fed or not fed gossypol. Embryo donor heifers consumed either 0 or $12 \mathrm{~g} / \mathrm{d}$ of free gossypol for 76 $\mathrm{d}$ prior to embryo collection, resulting in mean plasma gossypol concentrations of 0 and $7.38 \mu \mathrm{g} / \mathrm{mL}$, respectively. Embryos were transferred on $d 7$ of the estrous cycle and pregnancy diagnosed 21 and $35 \mathrm{~d}$ later. Progesterone was analyzed in plasma collected on $\mathrm{d} 5$ and 12 of the estrous cycle. Treatment with hCG increased the total luteal area on $\mathrm{d} 12\left(818.0\right.$ vs. $\left.461.1 \mathrm{~mm}^{2}\right)$ because of increased number of corpora lutea ( $2.0 \mathrm{vs}$. 1.0) and increased area of the original corpora lutea $\left(522.7\right.$ vs. $\left.443.5 \mathrm{~mm}^{2}\right)$. Plasma progesterone concentrations were similar between treatments on d 5 , but increased by d 12 in hCG-treated cows (6.46 vs. $4.78 \mathrm{ng} /$ $\mathrm{mL}$ ). Pregnancy rates on $\mathrm{d} 28$ and 42 were not affected by hCG. However, after transfer into lactating cows, embryos collected from heifers not fed gossypol resulted in higher pregnancy rates at $28 \mathrm{~d}$ (33.3 vs. $23.1 \%$ ) and 42 d (29.6 vs. $20.2 \%)$ of gestation compared with embryos collected from heifers fed gossypol. Our data suggest that the negative effects of gossypol on fertility are mediated by changes in embryo viability in spite of similar grade quality at transfer.
\end{abstract}

Key words: gossypol, human chorionic gonadotropin, embryo survival, dairy cow

\section{INTRODUCTION}

Cottonseed is commonly fed to cattle as a source of protein, fat, and fiber, but it contains gossypol, a toxic yellow pigment (a polyphenolic binaphthyl dialdehyde)

Received November 30, 2005.

Accepted January 17, 2006.

${ }^{1}$ Corresponding author: Jsantos@vmtrc.ucdavis.edu found primarily in the pigment glands of the seed (Ponday and Thejappa, 1975). Gossypol binds to the lipid portion of cell membranes (Reyes et al., 1984) and disrupts mechanisms of energy generation (Abou-Donia and Dieckert, 1974). It has been shown to decrease anion transport and glucose uptake and increase free radical generation (Reyes et al., 1984; Kanwar et al., 1990), which may affect early embryo development in vitro (Zirkle et al., 1988; Brocas et al., 1997). Feeding different amounts of gossypol from different types of cottonseeds raised total plasma gossypol concentrations above $5 \mu \mathrm{g} / \mathrm{mL}$ in lactating dairy cows (Santos et al., 2003) and Holstein heifers (Villaseñor et al., 2003). The increase in plasma gossypol negatively affected fertility of lactating dairy cows (Santos et al., 2003) and embryo quality in vivo (Randel et al., 1996) and in vitro (Brocas et al., 1997). Furthermore, Villaseñor et al. (2003) observed that, despite similar grade quality of embryos collected on d 5 after AI, those from heifers fed gossypol had fewer blastomeres and retarded development in vitro. Therefore, embryos collected from heifers fed gossypol may lead to lower fertility after embryo transfer.

Luteal activity has been associated with capacity of embryos to secrete IFN- $\tau$ and block the luteolytic cascade (Mann and Lamming, 2001). Administration of human chorionic gonadotropin (hCG) during the early luteal phase induced ovulation of the first-wave dominant follicle, led to the formation of a functional accessory corpus luteum (CL), increased progesterone concentration in plasma (Diaz et al., 1998), and increased pregnancy rates in beef cows after embryo transfer (Nishigai et al., 2002) and in dairy cows after AI (Santos et al., 2001). Therefore, hCG may improve embryo survival in recipient dairy cows by enhancing luteal function.

We hypothesized that embryos collected from gossypol-fed donor heifers would result in lower embryonic survival after transfer into recipient lactating dairy cows, and that treatment of recipient cows with hCG would enhance luteal function and improve pregnancy rates. The objective of this study was to determine the effect of exposure to gossypol during early embryo development in donor heifers on embryonic survival after transfer of frozen and thawed embryos to lactating dairy cows treated with hCG on $\mathrm{d} 5$ of the estrous cycle. 


\section{MATERIALS AND METHODS}

\section{Animals, Housing, and Feeding}

The University of California-Davis Institutional Animal Care and Use Committee approved all procedures involving animals. Two hundred sixty-nine lactating Holstein cows (93 primiparous and 176 multiparous) from a high-producing commercial dairy farm located in the Central Valley of California were enrolled in the study at $70 \pm 3 \mathrm{~d}$ postpartum (study d 0) from August 2002 to February 2003, and the study was completed in April of 2003. The lactating herd size during the study was 880 cows and the 3.5\% FCM rolling-herd average was $11,590 \mathrm{~kg} / \mathrm{cow}$.

Cows were housed in freestall barns equipped with fans and sprinklers that were activated during the hot months of the year when environmental temperature rose above $26^{\circ} \mathrm{C}$. Cows were enrolled during periods of heat stress (August to September 2002) or thermoneutral temperature (October 2002 to February 2003). The mean $( \pm \mathrm{SD})$ daily average and daily maximum temperatures for the heat stress and thermoneutral periods were $25.2 \pm 2.8^{\circ} \mathrm{C}$ and $34.4 \pm 4.0^{\circ} \mathrm{C}$, and $12.7 \pm 3.9^{\circ} \mathrm{C}$ and $18.5 \pm 5.3^{\circ} \mathrm{C}$, respectively. Daily average temperatures ranged from 18.3 to $29.4^{\circ} \mathrm{C}$ and from 2.8 to $26.1^{\circ} \mathrm{C}$ for the heat-stress and thermoneutral periods, respectively.

Primiparous and multiparous cows were housed in the same barn, but in separate pens throughout the study and were fed the same diet as a TMR, twice daily, to meet or exceed the dietary requirements for a lactating cow weighing $680 \mathrm{~kg}$ and producing $45 \mathrm{~kg}$ of $3.5 \%$ FCM (NRC, 2001). Cows were milked twice daily and production was measured for individual cows once monthly during the official California DHIA milk test performed by the DHIA laboratory in Hanford, CA. Milk yields during the first 3 mo postpartum were used to assess the effects of milk yield on reproductive responses. All recipient cows had their BCS evaluated using a 5 -point ( $1=$ thin to $5=$ fat) scoring system (Ferguson et al., 1994) at study enrollment.

\section{Diets, Superovulatory Treatments, Embryo Collection, and Freezing}

Holstein heifers $(n=81)$ were randomly assigned to consume either 0 or $12 \mathrm{~g} / \mathrm{d}$ of free gossypol during 76 d before embryo collection, which resulted in mean plasma gossypol concentrations of 0 and $7.38 \mu \mathrm{g} / \mathrm{mL}$. Heifers were housed in open corrals, and diets were offered as component-fed, with concentrate fed once daily separately from the forage. The forage component of the diet, a blend of alfalfa and wheat hay (2:1), was offered for ad libitum intake. Concentrates were offered at $2.2 \mathrm{~kg}$ of $\mathrm{DM} /$ heifer per day and were formulated to be isonitrogenous and isocaloric, but to vary in the amount of free gossypol content by adding cracked Pima cottonseed (Gossypium barbedense). Heifers in the nogossypol treatment ( $\mathrm{n}=40 ; 0 \mathrm{~g} / \mathrm{d}$ of free gossypol) received a concentrate containing (DM basis) $44.0 \%$ almond hulls, $30.0 \%$ soybean meal, $15.0 \%$ beef tallow, $6.7 \%$ monensin supplement to supply $200 \mathrm{mg}$ of monensin, and $4.3 \%$ mineral and vitamin supplement. Heifers in the gossypol treatment ( $\mathrm{n}=41 ; 12 \mathrm{~g} / \mathrm{d}$ of free gossypol) received a concentrate containing (DM basis) $55.0 \%$ cracked Pima cottonseed, $10.0 \%$ steam-flaked corn, $16.0 \%$ almond hulls, $5.0 \%$ soybean meal, $3.0 \%$ beef tallow, $6.7 \%$ monensin supplement to supply $200 \mathrm{mg}$ of monensin, and $4.3 \%$ mineral and vitamin supplement. Diets were offered to meet the nutrient requirements of Holstein heifers weighing $400 \mathrm{~kg}$ and gaining $0.7 \mathrm{~kg} /$ d (NRC, 2001), considering the daily average forage intake of $4.5 \mathrm{~kg} / \mathrm{heifer}$ based upon daily group intake.

Concentrates and hays were sampled weekly, dried at $55^{\circ} \mathrm{C}$ for $48 \mathrm{~h}$, ground in a Wiley mill (Arthur $\mathrm{H}$. Thomas Co., Philadelphia, PA), frozen, and later analyzed for $\mathrm{DM}$ at $105^{\circ} \mathrm{C}$, as well as $\mathrm{OM}$, ether extract, $\mathrm{CP}$, $\mathrm{NDF}$, and ADF. The composition of the concentrates for the no-gossypol and gossypol treatments were, respectively, 21.3 and $21.5 \% \mathrm{CP}, 17.9$ and $18.8 \%$ ether extract, 12.4 and $19.9 \% \mathrm{ADF}$, and 3.45 and $3.54 \mathrm{Mcal}$ of $\mathrm{ME} /$ $\mathrm{kg}$ (NRC, 2001). Cottonseed was analyzed for free and total gossypol content in decorticated seeds as described previously (Mena et al., 2001). Pima cottonseed contained $1.10 \%$ total gossypol and $1.03 \%$ free gossypol, with a ratio of 47.1 to $52.9 \%$ plus and minus isomers, respectively.

A blood sample $(20 \mathrm{~mL})$ was collected from each heifer the day before uterine flushing by puncture of the median coccygeal vein or artery using heparinized Vacutainer (Becton Dickinson and Co., Franklin Lakes, NJ) tubes. Blood tubes were immediately placed in ice and transported to the laboratory within $1 \mathrm{~h}$ of collection. Tubes were centrifuged at $2,000 \times g$ for $10 \mathrm{~min}$ at $10^{\circ} \mathrm{C}$ for plasma separation. The plasma was then frozen at $-25^{\circ} \mathrm{C}$ and later analyzed for total gossypol and gossypol isomers by HPLC as described previously (Mena et al., 2001).

Six days after being observed in estrus, all heifers received a controlled intravaginal drug releasing (CIDR) insert containing $1.38 \mathrm{~g}$ of progesterone (EAZIBREED, Pfizer Animal Health, New York, NY) and an i.m. injection of $2 \mathrm{mg}$ of estradiol benzoate ( $\beta$-estradiol 3-benzoate, E-8515, Sigma Chemical Co., St. Louis, MO) $24 \mathrm{~h}$ later. The superovulatory treatment was initiated $4 \mathrm{~d}$ after the injection of estradiol benzoate with decreasing, twice-daily doses of FSH $(300 \mathrm{mg} / \mathrm{heifer}$, Folltropin-V, Vetrepharm Inc., Canada) during $4 \mathrm{~d}$. Two 
i.m. injections of $25 \mathrm{mg}$ of $\mathrm{PGF}_{2 \alpha}$ (Lutalyse, $5 \mathrm{mg} / \mathrm{mL}$ dinoprost tromethamine, Pfizer Animal Health) were administered at the same time as seventh and eighth FSH injections, and the CIDR insert was removed concomitantly with the last FSH treatment. Heifers were observed for estrus twice daily and AI was performed twice, $12 \mathrm{~h}$ apart, with the first AI when the animal was detected in estrus. Semen from 2 sires was randomly allocated across treatments.

Uteri of heifers were flushed $7 \mathrm{~d}$ after the initial AI with embryo flushing solution containing $0.1 \%$ albumin and $25 \mathrm{mg} / \mathrm{L}$ kanamycin sulfate (Sterile Filtered Embryo Flushing Solution, PETS, Inc., Canton, TX) in a standard nonsurgical procedure. The recovered flush was filtered and embryos were classified in accordance to guidelines suggested by the International Embryo Transfer Society for developmental stage (morula, early blastocyst, blastocyst, and expanded blastocyst) and grade quality (excellent, good, fair, and degenerate). Only embryos graded as excellent and good were frozen in Dulbecco's-modified PBS enriched with 1.5 M ethylene glycol, $0.4 \% \mathrm{BSA}$, and $0.1 M$ sucrose.

\section{Synchronization of Ovulation in Recipient Cows and Embryo Transfer}

Every week, a group of 10 to 20 cows past $60 \mathrm{~d}$ postpartum had their ovulation synchronized using the Ovsynch protocol, which consisted of GnRH, $100 \mu \mathrm{g}$ i.m. (Fertagyl, $50 \mu \mathrm{g} / \mathrm{mL}$ gonadorelin diacetate tetrahydrate, Intervet, Inc., Millsboro, DE), followed $7 \mathrm{~d}$ later by an i.m. injection of $25 \mathrm{mg}$ of $\mathrm{PGF}_{2 \alpha}$, and an i.m. injection of $100 \mu \mathrm{g}$ of $\mathrm{GnRH} 48 \mathrm{~h}$ after the $\mathrm{PGF}_{2 \alpha}$. During the Ovsynch, a CIDR was inserted at the first GnRH injection and removed at the $\mathrm{PGF}_{2 \alpha}$ injection to avoid estrous behavior during the protocol and improve synchronization of ovulation. The day of the last GnRH injection of the Ovsynch was considered estrous cycle d 0 (Figure 1).

Only recipient cows that responded to the synchronization of ovulation protocol, as determined by ovulation of the dominant follicle within $48 \mathrm{~h}$ after the final $\mathrm{GnRH}$ of the Ovsynch protocol and the presence of the corresponding CL on $d 5$ of the estrous cycle, received an embryo transferred through a nonsurgical procedure on $\mathrm{d} 7$ of the estrous cycle. Embryos were thawed in air for $15 \mathrm{~s}$ and in water at $35^{\circ} \mathrm{C}$ for $30 \mathrm{~s}$. After thawing, embryos were reevaluated before transfer and only those graded as excellent and good were transferred, with the exception of 9 embryos that were graded as fair. The same technician transferred all embryos and only one embryo was transferred per recipient cow to the uterine horn ipsilateral to the ovary bearing the CL.

\section{Treatments}

Treatments were arranged in a $2 \times 2$ factorial design with 2 embryo donor treatments and 2 recipient cow treatments. Recipient cows received either an i.m. injection of 3,300 IU of hCG (Chorulon, Intervet, Inc.) or no treatment on $d 5$ of the estrous cycle, and on $d 7$ of the estrous cycle they received embryos collected from donor heifers fed or not fed gossypol (Figure 1). This arrangement generated 4 possible treatment combinations: hCG recipient + control (no gossypol) embryo ( $\mathrm{n}=$ $69)$; hCG recipient + gossypol embryo $(\mathrm{n}=66)$; no $\mathrm{hCG}$ recipient + control embryo $(\mathrm{n}=66)$; and no hCG recipient + gossypol embryo $(n=68)$.

\section{Ovarian Ultrasonography}

Ultrasonographic examination of the ovaries was performed using a $7.5-\mathrm{MHz}$ linear transducer (Sonovet 2000, Universal Medical System, Bedford Hills, NY) at all injections of the ovulation synchronization protocol (Ovsynch), and again at d 2, 5, and 12 of the estrous cycle (Figure 1). A map of each ovary was drawn to include the location and size of follicles with diameter $>5 \mathrm{~mm}$ and CL. The vertical and horizontal greater diameters of the CL were recorded to calculate its area, assuming it had an elliptical shape. These examinations allowed determining success of synchronization of ovulation and responses to hCG injection on $\mathrm{d} 5$. Ovulation was characterized by the disappearance of one or more dominant follicles from the ovaries $48 \mathrm{~h}$ after the second GnRH treatment of the Ovsynch protocol and appearance of one or more CL on d 5 of the estrous cycle. Ovulation after the hCG injection was characterized by the disappearance of one or more dominant follicles from the ovaries on $\mathrm{d} 5$ and appearance of one or more accessory CL on 12 of the estrous cycle.

\section{Blood Sampling and Progesterone Analysis}

Blood samples were collected from all cows for measurement of progesterone concentrations in plasma. The first blood sample was collected on $\mathrm{d} 5$ of the estrous cycle at the time of recipient treatment with hCG, and the second sample was collected on $\mathrm{d} 12$ of the estrous cycle (Figure 1). This sampling scheme allowed evaluation of the effect of hCG treatment of recipient cows on d 5 of the estrous cycle on progesterone concentrations on d 12 of the estrous cycle.

Approximately $7 \mathrm{~mL}$ of blood was collected by puncture of the median coccygeal vein or artery using Vacutainer tubes (Becton, Dickinson and Co.) containing sodium EDTA. The samples were immediately placed in ice and later centrifuged at 2,000 $\times g$ for 15 min for 


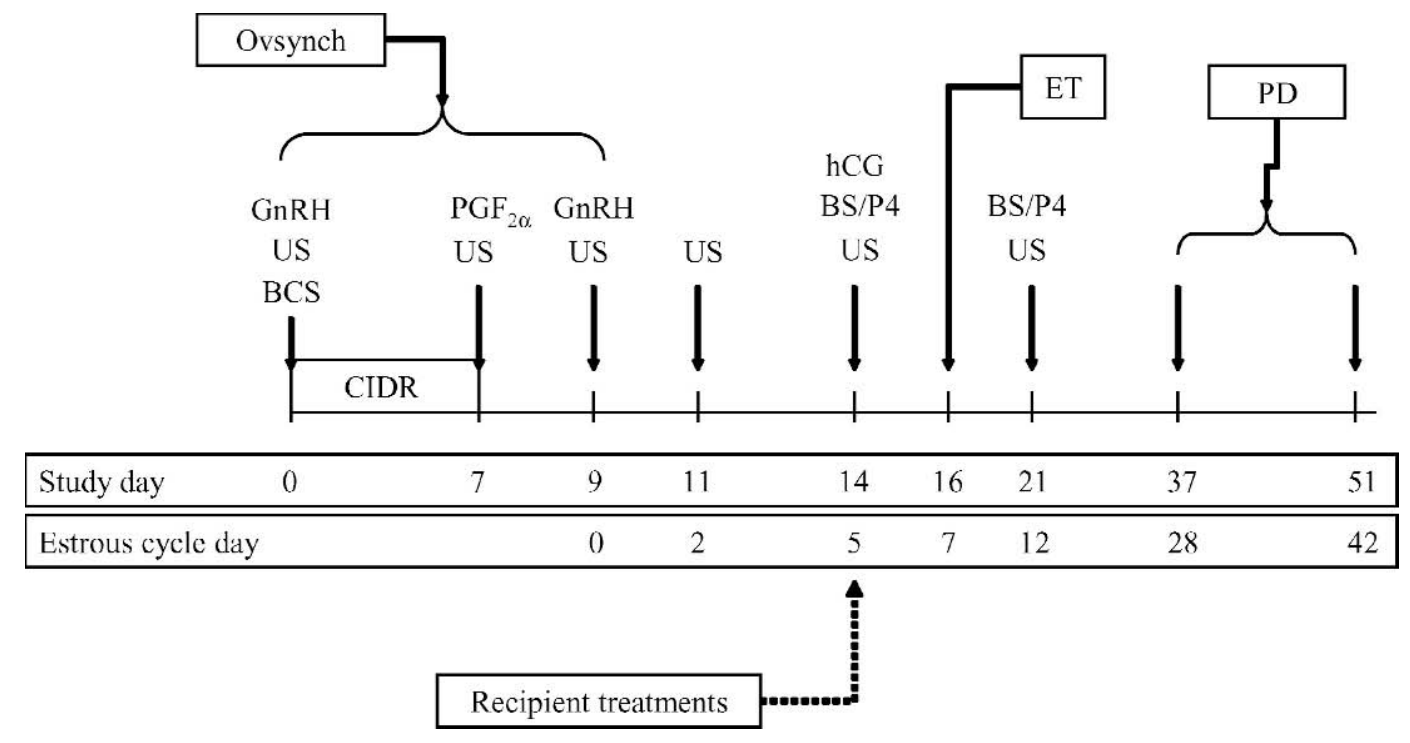

Figure 1. Diagram of activities during the study. $\mathrm{GnRH}=$ injection of $100 \mu \mathrm{g}$ of gonadorelin; $\mathrm{PGF}_{2 \alpha}=$ injection of $25 \mathrm{mg}$ of prostaglandin $\mathrm{F}_{2 \alpha} ; \mathrm{CIDR}=$ controlled intravaginal drug releasing insert containing $1.38 \mathrm{~g}$ of progesterone; US = ultrasonographic examination of ovaries; hCG = injection of 3,300 IU i.m. of human chorionic gonadotropin; BS/P4 = blood sampling for progesterone analysis; ET = embryo transfer; $\mathrm{PD}=$ pregnancy diagnosis.

separation of plasma. Plasma samples were frozen at $-25^{\circ} \mathrm{C}$ until later analysis.

Progesterone was analyzed by ELISA (Munro and Stabenfeldt, 1984) validated for our laboratory with the following modifications: blood was collected from a young male calf and plasma was separated. A charcoalstripping procedure was utilized to remove any progesterone and other steroids from plasma that could crossreact during the assay. Charcoal-stripped plasma enriched with known concentrations of progesterone was used as a quality control in each 96 -well plate to determine the efficiency of progesterone recovery. A secondary goat antimouse antibody was added to the microplates prior to the primary monoclonal progesterone antibody. Intraassay coefficient of variation was determined for each 96-well plate, and a plasma sample with $3.0 \mathrm{ng} / \mathrm{mL}$ of progesterone was used in each plate to estimate the interassay coefficient of variation. The sensitivity of the assay was $0.05 \mathrm{ng} / \mathrm{mL}$, and the intraand interassay coefficients of variation were 5.8 and $6.3 \%$, respectively.

\section{Pregnancy Diagnosis and Reproductive Outcomes}

All cows were examined for pregnancy by ultrasonography on d 28 of gestation, which corresponded to $\mathrm{d} 21$ after embryo transfer. The detection of an embryonic vesicle with a viable embryo (presence of heartbeat) was used as an indicator of pregnancy. Cows diagnosed as pregnant were palpated per rectum for detection of an embryonic vesicle to confirm pregnancy and determine late embryonic loss on gestation d 42. Pregnancy rate was defined as the number of pregnant cows at gestation d 28 and 42 relative to the total number of cows in each treatment group. Late embryonic loss, between d 28 and 42 of gestation, was characterized by cows diagnosed with a viable pregnancy on $\mathrm{d} 28$, but nonpregnant on d 42.

\section{Statistical Analyses}

The experiment was a randomized complete block design. Weekly, a cohort of 10 to 20 cows was blocked according to lactation number (primiparous or multiparous), days postpartum, and BCS at first GnRH of the Ovsynch and, within each block, randomly assigned to 1 of the 4 treatments arranged in a $2 \times 2$ factorial arrangement.

Dichotomous outcomes, such as ovulation rate, pregnancy rate, and late embryonic loss were analyzed by logistic regression using the LOGISTIC procedure of SAS (SAS Institute, 2001). A backward stepwise regression model was utilized. The full model for analyses of pregnancy rate and late embryonic loss included the effects of embryo treatment, recipient treatment, interaction between embryo and recipient treatments, embryo grade quality, embryo stage of development, parity, season, BCS, average milk production during the first 3 mo postpartum, progesterone concentration on $\mathrm{d} 5$ and 12 of the estrous cycle, and interactions between 
embryo treatment or recipient treatment and other explanatory variables. Milk production was classified as above or below the mean yield for primiparous (35.0 $\mathrm{kg} / \mathrm{d}$ ) and multiparous cows $(46.7 \mathrm{~kg} / \mathrm{d})$. Progesterone concentrations were included in the model as a continuous variable. For analyses of ovulation rate in response to treatment with hCG, the model included the effects of recipient treatment, parity, BCS, milk yield, follicle diameter on d 5 of the estrous cycle, and interactions between recipient treatment and other explanatory variables. Variables were continuously removed from the model by the Wald statistic criterion if $P>0.20$.

Progesterone concentrations were analyzed by ANOVA (Littell et al., 2002) for repeated measures using the MIXED procedure of SAS (SAS Institute, 2001) with a model that included the effects of recipient treatment, embryo treatment, interaction between recipient and embryo treatments, parity, BCS, milk yield, season, and recipient cow within treatment as the random experimental error. The autoregressive 1 covariance structure was used to account for within cow correlation as this structure resulted in the model with best fit for the data based on the Schwartz's Bayesian criterion. Other continuous data such as CL area and size of the ovulatory follicles were analyzed by ANOVA (Littell et al., 2002) using the GLM procedure of SAS (SAS Institute, 2001) with an statistical model that included the effects of recipient treatment, embryo treatment, interaction between recipient and embryo treatments, parity, season, BCS, milk yield, interactions between treatments and other explanatory variables, and the random experimental error.

The nonparametric Kruskal-Wallis test in SAS (SAS Institute, 2001) was used to compare the median number of CL on d 5 and 12 of the estrous cycle. The mean $( \pm$ SEM) number of CL was evaluated by ANOVA, but the significance value was obtained using the GENMOD procedure of SAS (SAS Institute, 2001) after fitting a Poisson distribution and using a log transformation function. Treatment differences with $P \leq 0.05$ were considered significant and $0.05<P \leq 0.10$ were designated as a tendency toward a difference between treatments.

\section{RESULTS}

The mean and median number of CL and total CL area on $\mathrm{d} 5$ of the estrous cycle were not different $(P>$ $0.10)$ between hCG-treated and nontreated recipient cows, but hCG-treated cows had both a greater $(P<$ $0.01)$ mean and median number of CL and larger $(P<$ 0.01 ) total CL area on $d 12$ of the estrous cycle (Table $1)$. The area of the original CL was larger $(P<0.01)$ for hCG- than for non-hCG-treated cows on $\mathrm{d} 12$. The percentage of cows with an accessory CL on $\mathrm{d} 12$ of the estrous cycle induced by treatment on $\mathrm{d} 5$ was greater $(P<0.01)$ for hCG-treated cows compared with nonhCG-treated cows (Table 1).

There was an effect of size of dominant follicle on $d$ 5 of the estrous cycle on ovulatory response after hCG administration. Follicles with diameters of 8 to $10 \mathrm{~mm}$ on d 5 were classified as $\leq 10 \mathrm{~mm}$ and those between 11 and $21 \mathrm{~mm}$ in diameter were classified as $>10 \mathrm{~mm}$. Cows treated with hCG and having $\leq 10 \mathrm{~mm}$ follicles had a lower $(P<0.01)$ ovulation rate than cows with follicles $>10 \mathrm{~mm}$ in diameter (Figure 2). However, among cows that responded to hCG treatment and ovulated, double ovulation after hCG administration was greater $(P=0.01)$ for cows whose dominant follicle was $\leq 10 \mathrm{~mm}$ in diameter compared with cows with follicles $>10 \mathrm{~mm}$ (Figure 2). Overall, 92.6\% of the hCG-treated cows responded to treatment by ovulating, and $24.8 \%$ of the cows that ovulated experienced double ovulation.

Mean plasma progesterone concentration was not different $(P=0.26)$ for hCG-treated and non-hCG-treated cows on d 5, but treatment with hCG increased $(P<$ 0.01 ) progesterone concentrations on $\mathrm{d} 12$ of the estrous cycle as indicated by the interaction $(P<0.001)$ between treatment and day of the estrous cycle on progesterone concentrations (Figure 3). Concentrations of progesterone in recipient cows were not affected $(P>0.10)$ by season, parity, BCS, or milk yield.

Pregnancy rates were not affected by hCG treatment, but were reduced by embryo donor treatment with gossypol (Table 2). Lactating recipient cows treated with hCG had similar pregnancy rates to cows not treated with hCG on d 28 and 42 of gestation. Furthermore, progesterone concentrations on $\mathrm{d} 12$ of the estrous cycle did not influence pregnancy rates on d $28(P=0.98)$ and d $42(P=0.95)$ of gestation. However, control embryos were more likely $(P=0.04)$ to result in pregnancy than gossypol embryos [33.3 vs. $23.1 \%$; adjusted odds ratio $(\mathbf{A O R})=1.89 ; 95 \%$ confidence interval $(\mathbf{C I})=1.05$ to 3.41] on d 28 of gestation. Pregnancy rate on $d 42$ of gestation followed the same pattern of $\mathrm{d} 28$ tended to be greater $(P=0.06)$ for control than for gossypol embryos (29.6 vs. $20.2 \%$; $\mathrm{AOR}=1.79 ; 95 \% \mathrm{CI}=0.98$ to 3.28$)$. During the study period, pregnancy rates to AI for lactating cows inseminated in this herd were $32.0 \%$ (171/ 534) for first postpartum AI and 30.7\% (98/319) for the second postpartum AI, which were similar to results obtained for cows receiving control embryos.

In addition to embryo treatment, season when embryos were transferred influenced pregnancy rates on d 28. Embryos transferred during heat stress were less likely to survive and resulted in a lower $(P=0.01)$ pregnancy rate on d 28 of gestation ( $17.1 \mathrm{vs.} 32.6 \%$; $\mathrm{AOR}=0.39 ; 95 \% \mathrm{CI}=0.19$ to 0.80$)$ and tended to result 
Table 1. Effect of treatment with human chorionic gonadotropin (hCG) on d 5 of the estrous cycle on ovarian dynamics of embryo-recipient lactating dairy cows

\begin{tabular}{lcccr}
\hline & \multicolumn{2}{c}{ Recipient $^{\text {treatment }}{ }^{1}$} & & \\
\cline { 2 - 3 } Variable & No hCG & hCG & SEM & $P<$ \\
\hline Mean number of corpora lutea (CL) on d 5 & 1.08 & 1.06 & 0.02 & 0.49 \\
Median number of CL on d 5 & 1.0 & 1.0 & 0.33 \\
Mean number of CL on d 12 & 1.1 & 2.2 & 0.01 \\
Median number of CL on d 12 & 1.0 & 292.7 & - & 0.01 \\
Total CL area on d 5 $\left(\mathrm{mm}^{2}\right)$ & 296.9 & 818.0 & 9.9 & 0.74 \\
Total CL area on d 12 $\left(\mathrm{mm}^{2}\right)$ & 461.1 & 522.7 & 18.7 & 0.01 \\
Area of original CL on d 12 $\left(\mathrm{mm}^{2}\right)$ & 443.5 & & 15.3 & 0.01 \\
Accessory CL on d 12, \% $(\mathrm{n} / \mathrm{n})^{2}$ & $1.5(2 / 134)$ & $92.6(125 / 135)$ & - & 0.01 \\
Mean follicle size on d 5 (mm) & 13.2 & 12.9 & 0.2 & 0.32 \\
\hline
\end{tabular}

${ }^{1} \mathrm{No}$ hCG $=$ no hCG administration on $\mathrm{d} 5$ of the estrous cycle; hCG = injection of 3,300 IU i.m. of hCG on $\mathrm{d} 5$ of the estrous cycle.

${ }^{2}$ Number of cows evaluated by ultrasonography in each recipient treatment: No hCG $=134 ; \mathrm{hCG}=135$.

in a lower $(P=0.10)$ pregnancy rate on $\mathrm{d} 42(17.1 \mathrm{vs}$. $28.0 ; \mathrm{AOR}=0.55 ; 95 \% \mathrm{CI}=0.27$ to 1.12 ). Pregnancy rates on $\mathrm{d} 28$ and 42 and pregnancy losses were not influenced $(P>0.10)$ by parity or any other variable evaluated in the statistical model. Furthermore, there were no interactions between embryo treatment or recipient treatment and other explanatory variables on pregnancy rates or pregnancy loss.

\section{DISCUSSION}

As observed in previous studies, treatment with hCG on $\mathrm{d} 5$ led to an increased number of CL and total CL area on d 12 of the estrous cycle (Diaz et al., 1998;

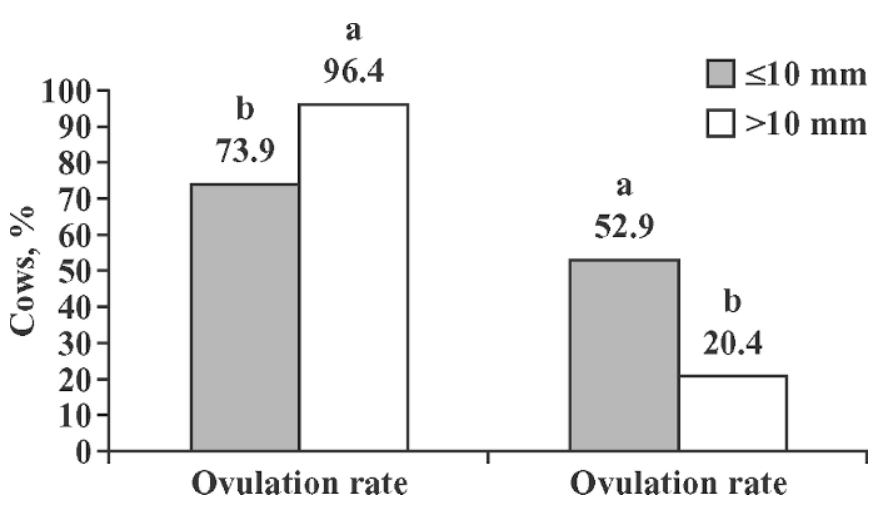

Figure 2. Ovulation rate for all cows that received an injection of 3,300 IU i.m. of human chorionic gonadotropin (hCG) on d 5 of the estrous cycle and double ovulation rate for cows that responded to hCG on d 5 of the estrous cycle according to dominant follicle size category. Number of cows evaluated for ovulation rate was 23 and 112 for dominant follicle diameter $\leq 10 \mathrm{~mm}$ (gray bars) and $>10 \mathrm{~mm}$ (open bars), respectively. Number of cows that responded to hCG and evaluated for double ovulation rate was 17 and 108 for dominant follicle diameter $\leq 10 \mathrm{~mm}$ (gray bars) and $>10 \mathrm{~mm}$ (open bars), respectively. Within each parameter, bars with different superscripts differed $(P<0.01)$
Santos et al., 2001). Interestingly, the area of the original CL was increased by hCG treatment, which is in agreement with studies in which the original CL size increased between $\mathrm{d} 9$ and 13 of the estrous cycle when hCG treatment was applied on d 6 of the estrous cycle (Nishigai et al., 2001). A plausible explanation for the increased size of the original CL could be the increased size of small and large luteal cells from the original CL observed by Schmitt et al. (1996) or the increased proportion of large luteal cells (Farin et al., 1988) observed after hCG administration early in the estrous cycle.

The effects of hCG on follicular and luteal function have been well characterized (Schmitt et al., 1996; Diaz

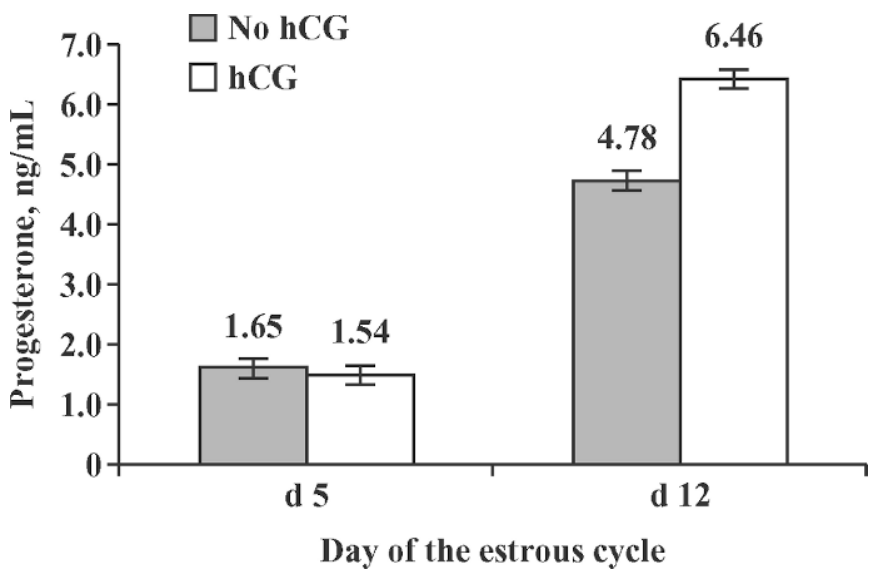

Figure 3. Least squares mean $( \pm \mathrm{SEM})$ of concentrations of progesterone in plasma $(\mathrm{ng} / \mathrm{mL})$ on $\mathrm{d} 5$ and 12 of the estrous cycle for cows that did not receive an injection of 3,300 IU i.m. of human chorionic gonadotropin (hCG) on d 5 of the estrous cycle (No hCG; gray bars) or cows that received an injection of 3,300 IU i.m. of hCG on d 5 of the estrous cycle (hCG; open bars). Effect of hCG, $P<0.01$; day of the estrous cycle, $P<0.01$; interaction between hCG and day of the estrous cycle, $P<0.01$. Number of cows in each of the 2 recipient treatments sampled for progesterone: $\mathrm{No}$ hCG $=134$; $\mathrm{hCG}=135$. 
Table 2. Effect of human chorionic gonadotropin (hCG) treatment on d 5 of the estrous cycle and embryo donor treatment with gossypol on pregnancy rates and late embryonic loss in lactating dairy cows

\begin{tabular}{|c|c|c|c|c|c|c|c|}
\hline \multirow[b]{3}{*}{ Embryo donor treatment ${ }^{2}$} & \multicolumn{4}{|c|}{ Recipient treatment $^{1}$} & \multicolumn{3}{|c|}{$P$} \\
\hline & \multicolumn{2}{|c|}{ No hCG } & \multicolumn{2}{|c|}{ hCG } & \multirow[b]{2}{*}{$\mathrm{hCG}$} & \multirow[b]{2}{*}{ Gossypol } & \multirow{2}{*}{$\begin{array}{l}\text { hCG } \times \\
\text { Gossypol }^{3}\end{array}$} \\
\hline & Gossypol & No gossypol & Gossypol & No gossypol & & & \\
\hline \multicolumn{8}{|l|}{ Pregnancy rate, $\%(n / n)$} \\
\hline d 28 & $23.5(16 / 68)$ & $31.8(21 / 66)$ & $22.7(15 / 66)$ & $34.8(24 / 69)$ & 0.94 & 0.04 & 0.87 \\
\hline d 42 & $19.1(13 / 68)$ & $28.8(19 / 66)$ & $21.2(14 / 66)$ & $30.4(21 / 69)$ & 0.95 & 0.06 & 0.87 \\
\hline \multicolumn{8}{|l|}{ Late embryonic loss, \% } \\
\hline
\end{tabular}

${ }^{1} \mathrm{No} h C G=$ no hCG treatment of recipient cows on d 5 of the estrous cycle; hCG = injection of 3,300 IU i.m. of hCG on d 5 of the estrous cycle.

${ }^{2}$ Gossypol = embryos collected from Holstein heifers fed $12 \mathrm{~g}$ of free gossypol/day for $76 \mathrm{~d}$ prior to embryo collection; No gossypol = embryos collected from Holstein heifers fed no gossypol.

${ }^{3} \mathrm{hCG} \times$ Gossypol $=$ interaction between $\mathrm{hCG}$ and gossypol.

et al., 1998). The induction of ovulation in $92.6 \%$ of the cows after hCG administration on d 5 of the estrous cycle is slightly greater than the results observed by Santos et al. (2001), who reported that $86.2 \%$ of lactating Holstein cows treated with 3,300 IU of hCG on d 5 of the estrous cycle had an accessory CL on d 14 of the cycle compared with $23 \%$ of non-hCG-treated cows. It is noteworthy that, in the current study, only cows with confirmed ovulation within $48 \mathrm{~h}$ after the final $\mathrm{GnRH}$ injection of the ovulation synchronization protocol were enrolled and received hCG on d 5 of the estrous cycle. Therefore, the high ovulatory response to hCG treatment was likely due to the synchrony of follicle growth. Two recipient cows assigned to the non-hCG treatment presented an accessory CL at the ultrasonographic examination on d 12 of the estrous cycle. This finding could be due to a missed double ovulation after synchronized ovulation with the Ovsynch protocol.

The rate of double ovulation $(24.8 \%)$ for cows that responded to hCG treatment was similar to that observed when cows received 4 to $40 \mathrm{mg}$ of $\mathrm{LH}$ early in the estrous cycle (Sartori et al., 2001). Follicle deviation and acquisition of ovulatory capacity occurs when follicles reach a diameter of 8 to $10 \mathrm{~mm}$ (Sartori et al., 2001). Higher double ovulation for cows with small dominant follicles indicates that hCG given on $\mathrm{d} 5$ of the estrous cycle may interfere with the process of follicle deviation. Lopez et al. (2004) observed an increased LH concentration in cows with multiple compared with single ovulation, which indicates that $\mathrm{LH}$, and possibly hCG, may stimulate the acquisition of ovulatory capacity. Sartori et al. (2001) observed an abnormally high rate of codominance $(86.7 \%)$ in cows that did not ovulate after treatment with $40 \mathrm{mg}$ of $\mathrm{LH}$, and observed a recovery of $35 \%$ of subordinated follicles in cows that ovulated after treatment with 24 or $40 \mathrm{mg}$ of $\mathrm{LH}$. It is possible that ovulation of recovered subordinated follicles may be induced due to the longer half-life of hCG.
In spite of the successful induction of ovulation, formation of an accessory CL, and increased concentrations of progesterone in plasma, hCG treatment had no effect on establishment of pregnancy in recipient cows as indicated by the similar pregnancy rates and late embryonic loss. Decreased fertility has been associated with reduced luteal function (Larson et al., 1997). However, plasma progesterone concentrations on d 5 and 12 of the estrous cycle were not associated with pregnancy rates in this study, indicating that factors other than progesterone concentrations were more important for establishment of pregnancy.

One of our hypotheses was that gossypol would reduce embryonic survival and compromise pregnancy establishment in recipient lactating dairy cows. In studies with beef cattle in vivo, feeding of gossypol had mixed effects on reproductive parameters (Gray et al., 1993; Randel et al., 1996). Beef heifers fed $5 \mathrm{~g} / \mathrm{d}$ of free gossypol from cottonseed meal had a greater proportion of recovered embryos classified as degenerated when compared with heifers fed $15 \mathrm{~g} / \mathrm{d}$ of free gossypol from whole cottonseed or no gossypol (Randel et al., 1996), but follicular steroidogenesis remained unaffected. Feeding of free gossypol from whole cottonseed or cottonseed meal did not affect luteal function in beef heifers (Gray et al., 1993; Randel et al., 1996) and beef cows (Gray et al., 1993), suggesting that a possible negative effect of gossypol on the fertility of female bovine is not related to luteal steroidogenesis. Studies in vitro have demonstrated that gossypol negatively affected embryo development when concentration in the culture media was as low as $5 \mu \mathrm{g} / \mathrm{mL}$ (Brocas et al., 1997). However, the negative effects on gametes and embryos usually increased in a dose-dependent manner (Zirkle et al., 1988; Brocas et al., 1997). Similarly, the negative effects of gossypol on fertility of lactating dairy cows were dependent upon concentrations of gossypol in plasma (Santos et al., 2003). 
In the current experiment, gossypol embryos were collected from heifers with a mean plasma gossypol concentration of $7.38 \mu \mathrm{g} / \mathrm{mL}$. In spite of similar grade quality at transfer, gossypol embryos resulted in lower pregnancy rates. These results indicate that gossypol affected embryos metabolically or physiologically in a way that impaired subsequent development despite similar grade quality immediately before transferring. Studies evaluating the effect of gossypol on fertility of cattle are scarce in the literature; in one report, feeding of gossypol did not influence pregnancy rate in beef heifers (Gray et al., 1993). Because free gossypol is detoxified in the rumen to bound gossypol, which has little or no impact on plasma gossypol concentrations (Mena et al., 2001), it is possible that differences in experimental results on the effects of gossypol on fertility of female bovine are associated with availability of gossypol for absorption and consequent changes in plasma and tissue gossypol concentrations.

Gossypol has been shown to bind to the lipid portion of cell membranes and change its interfacial potential (Reyes et al., 1984), disrupt mechanisms of energy generation by cells (Abou-Donia and Dieckert, 1974), decrease anion transport and cellular uptake of glucose, and increase free radical generation (Reyes et al., 1984; Kanwar et al., 1990). One or more of these factors could affect embryo development without necessarily affecting embryo microscopic morphology. Although embryos were reevaluated before transfer and only embryos graded as excellent and good were used in the current study, gossypol still had a carryover effect on pregnancy establishment. Villaseñor et al. (2003) observed that, despite similar grade quality of embryos collected on $d$ 5 after AI, those from heifers receiving $40 \mathrm{mg}$ of free gossypol/kg of BW per day, resulting in a daily intake of $15 \mathrm{~g}$ of free gossypol, had fewer blastomeres and had retarded development in vitro.

Although gossypol had a negative effect on pregnancy rates, it did not alter late embryonic loss in dairy cows. This indicates that the effect of gossypol was probably on early embryo viability as it has been demonstrated in vitro (Hernández-Cerón et al., 2005). However, continuous gossypol feeding and increase in plasma gossypol concentrations has been associated with increased pregnancy loss in lactating dairy cows (Santos et al., 2003).

Season when embryos were transferred influenced embryonic survival in lactating dairy cows. Heat stress has been shown to influence fertilization rate, oocyte viability, embryo development, and establishment of pregnancy in cattle (Putney et al., 1988; Sartori et al., 2002; Chebel et al., 2003). Putney et al. (1988) suggested that reduced fertility of cattle exposed to thermal stress might be caused by alterations in signals required for maintenance of the CL during early pregnancy.

In conclusion, treatment of embryo-recipient dairy cows with $3,300 \mathrm{IU}$ of hCG on d 5 of the estrous cycle successfully induced ovulation of the dominant follicle of the first follicular wave, formed an accessory CL, and increased progesterone concentrations. Ovulatory response of dominant follicles to hCG was size dependent, and small follicles were less responsive and resulted in a higher double ovulation after treatment. Treatment with hCG on d 5 of the estrous cycle neither counteracted the negative effects of gossypol nor improved pregnancy establishment in lactating Holstein cows after embryo transfer. Transfer of embryos collected from superovulated donor heifers that consumed $12 \mathrm{~g} / \mathrm{d}$ of free gossypol resulted in reduced pregnancy rates in lactating dairy cows despite similar grade quality at embryo transfer. Our data suggest that the negative effects of gossypol on fertility of dairy cows are mediated by changes in embryo viability.

\section{ACKNOWLEDGMENTS}

This study was supported by the University of California Davis Center for Food Animal Health grant to J.E. P. Santos. The authors would like to thank Intervet for donation of Fertagyl and Chorulon and Pfizer Animal Health for donation of Lutalyse. We want to thank the staff of Corcoran State Prison Dairy for allowing the use of their animals for this study.

\section{REFERENCES}

Abou-Donia, M. B., and J. W. Dieckert. 1974. Gossypol: Uncoupling of respiratory chain and oxidative phosphorylation. Life Sci. 14:1955-1963.

Brocas, C., R. M. Rivera, F. F. Paula-Lopes, L. R. McDowell, M. C. Calhoun, C. R. Staples, N. S. Wilkinson, A. J. Boning, P. J. Chenoweth, and P. J. Hansen. 1997. Deleterious actions of gossypol on bovine spermatozoa, oocytes, and embryos. Biol. Reprod. 57:901-907.

Chebel, R. C., J. E. P. Santos, J. P. Reynolds, R. L. Cerri, S. O. Juchem, and M. Overton. 2003. Factors affecting conception rate after artificial insemination and pregnancy loss in lactating dairy cows. Anim. Reprod. Sci. 84:239-255.

Diaz, T., E. J. Schmitt, R. L. de la Sota, M. J. Thatcher, and W. W. Thatcher. 1998. Human chorionic gonadotropin-induced alterations in ovarian follicular dynamics during the estrous cycle of heifers. J. Anim. Sci. 76:1929-1936.

Farin, C. E., C. L. Moeller, H. Mayan, F. Gamboni, H. R. Sawyer, and G. D. Niswender. 1988. Effect of luteinizing hormone and human chorionic gonadotropin on cell populations in the ovine corpus luteum. Biol. Reprod. 38:413-421.

Ferguson, J. D., D. T. Galligan, and N. Thomsen. 1994. Principal descriptors of body condition score in Holstein cows. J. Dairy Sci. 77:2695-2703.

Gray, M. L., L. W. Greene, and G. L. Williams. 1993. Effects of dietary gossypol consumption on metabolic homeostasis and reproductive endocrine function in beef heifers and cows. J. Anim. Sci. 71:3052-3059. 
Hernández-Cerón, J., F. D. Jousan, P. Soto, and P. J. Hansen. 2005. Timing of inhibitory actions of gossypol on cultured bovine embryos. J. Dairy Sci. 88:922-928.

Kanwar, U., R. Kaur, S. Chadha, and S. Sanyal. 1990. Gossypolinduced inhibition of glucose uptake in human ejaculate spermatozoa may be mediated by lipid peroxidation. Contraception 42:573-587.

Larson, S. F., W. R. Butler, and W. B. Currie. 1997. Reduced fertility associated with low progesterone postbreeding and increased milk urea nitrogen in lactating cows. J. Dairy Sci. 80:1288-1295.

Littell, R. C., W. W. Stroup, and R. J. Freund. 2002. SAS for Linear Models. 4th ed. SAS Inst., Inc., Cary, NC.

Lopez, H., R. Sartori, and M. C. Wiltbank. 2004. Reproductive hormones and follicular growth during development of one or multiple dominant follicles in cattle. Biol. Reprod. 72:788-795.

Mann, G. E., and G. E. Lamming. 2001. Relationship between maternal endocrine environment, early embryo development and inhibition of the luteolytic mechanism in cows. Reproduction 121:175-180.

Mena, H., J. E. P. Santos, J. T. Huber, J. S. Simas, M. Tarazon, and M. C. Calhoun. 2001. The effects of feeding varying amounts of gossypol from whole cottonseed and cottonseed meal in lactating dairy cows. J. Dairy Sci. 84:2231-2239.

Munro, C., and G. Stabenfeldt. 1984. Development of a microtitre plate enzyme immunoassay for the determination of progesterone. J. Endocrinol. 101:41-49.

Nishigai, M., H. Kamomae, T. Tanaka, and Y. Kaneda. 2002. Improvement of pregnancy rate in Japanese black cows by administration of hCG to recipients of transferred frozen-thawed embryos. Theriogenology 58:1597-1606.

Nishigai, M., A. Takamura, H. Kamomae, T. Tanaka, and Y. Kaneda. 2001. The effect of human chorionic gonadotropin on the development and function of bovine corpus luteum. J. Reprod. Dev. 47:283-294.

National Research Council. 2001. Nutrient Requirements of Dairy Cattle. 7th ed. Natl. Acad. Sci., Washington, DC.

Ponday, S. N., and N. Thejappa. 1975. Study on relationship between oil, protein and gossypol in cottonseed kernels. J. Am. Oil Chem. Soc. 52:312-315.

Putney, D. J., J. R. Malayer, T. S. Gross, W. W. Thatcher, P. J. Hansen, and M. Drost. 1988. Heat stress-induced alterations in the synthesis and secretion of proteins and prostaglandins by cultured bovine conceptuses and uterine endometrium. Biol. Reprod. 39:717-728.

Randel, R. D., S. T. Willard, S. J. Wyse, and L. N. French. 1996. Effects of diets containing free gossypol on follicular development, embryo recovery and corpus luteum function on Brangus heifers treated with bFSH. Theriogenology 45:911-922.

Reyes, J., J. Allen, N. Tanphaichitr, A. R. Bellve, and D. J. Benos. 1984. Molecular mechanisms of gossypol action on lipid membranes. J. Biol. Chem. 259:9607-9615.

Santos, J. E. P., W. W. Thatcher, L. Pool, and M. W. Overton. 2001. Effect of human chorionic gonadotropin on luteal function and reproductive performance of high-producing lactating Holstein dairy cows. J. Anim. Sci. 79:2881-2894.

Santos, J. E. P., M. Villaseñor, P. H. Robinson, E. J. DePeters, and C. A. Holmberg. 2003. Type of cottonseed and level of gossypol in diets of lactating dairy cows: Plasma gossypol, health, and reproductive performance. J. Dairy Sci. 86:892-905.

Sartori, R., P. M. Fricke, J. C. Ferreira, O. J. Ginther, and M. C. Wiltbank. 2001. Follicular deviation and acquisition of ovulatory capacity in bovine follicles. Biol. Reprod. 65:1403-1409.

Sartori, R., R. Sartor-Bergfelt, S. A. Mertens, J. N. Guenther, J. J. Parrish, and M. C. Wiltbank. 2002. Fertilization and early embryonic development in heifers and lactating cows in summer and lactating and dry cows in winter. J. Dairy Sci. 85:2803-2812.

SAS Institute. 2001. SAS/STAT User's Guide.Release 8.2. SAS Inst. Inc., Cary, NC.

Schmitt, E. J., T. Diaz, C. M. Barros, R. L. de la Sota, M. Drost, E. W. Fredriksson, C. R. Staples, R. Thorner, and W. W. Thatcher. 1996. A cellular and endocrine characterization of the original and induced corpus luteum after administration of a gonadotropinreleasing hormone agonist or human chorionic gonadotropin on day five of the estrous cycle. J. Anim. Sci. 74:1915-1929.

Villaseñor, M., A. C. Coscioni, K. N. Galvão, S. O. Juchem, J. E. P. Santos, and B. Puschner. 2003. Effect of gossypol intake on plasma and uterine gossypol concentrations and on embryo development and viability in vivo and in vitro. J. Dairy Sci. 86(Suppl. 1):240. (Abstr.)

Zirkle, S. M., Y. C. Lin, F. C. Gwazdauskas, and R. S. Canseco. 1988. Effect of gossypol on bovine embryo development during the preimplantation period. Theriogenology 30:575-582. 